\title{
Differential expression of microRNAs in the placentae of Chinese patients with severe pre-eclampsia
}

\author{
Yali $\mathrm{Hu}^{1,2}$, Pengfei $\mathrm{Li}^{3}$, Sha Hao ${ }^{3}$, Liu $\mathrm{Liu}^{3}$, \\ Junli Zhao ${ }^{3}$ and Yayi $\mathrm{Hou}^{2,3, *}$ \\ 1 The Affiliated Drum Tower Hospital of Nanjing \\ University Medical School, Nanjing 210008, \\ PR China \\ 2 Jiangsu Key Laboratory of Molecular Medicine, \\ Nanjing University, Nanjing 210093, PR China \\ ${ }^{3}$ Immunology and Reproductive Biology Lab, \\ Medical School and State Key Laboratory of \\ Pharmaceutical Biotechnology, Nanjing University, \\ Nanjing 210093, PR China
}

\begin{abstract}
Background: The pathogenesis of pre-eclampsia (PE) is incompletely understood. The placenta is considered to play a key role in this disease. Recent research showed that many microRNAs (miRNAs) are expressed in human placenta. Our aim in this study was to determine differential expression of miRNAs in placenta with severe $\mathrm{PE}$, and normal placenta.

Methods: Differential expression of miRNAs in placenta (four severe PE and a control group of four normal pregnant women) was first screened using microarray analysis. Following this, some differential miRNAs were selected and validated using real-time quantitative reverse transcription-polymerase chain reaction in placenta from women with severe $\mathrm{PE}$ $(n=24)$, and a healthy control group $(n=26)$.

Results: We found the following miRNAs were significantly increased in placenta from women with severe PE: miR-16, miR-29b, miR-195, miR-26b, miR181a, miR-335 and miR-222. Gene ontology analysis of the target genes revealed enrichment for specific biological process categories, i.e., regulation of cellular physiological process including miR-16, miR-29b, miR-195, miR-26b and miR-335, and signal transduction including miR-181a and miR-222.

Conclusions: These different miRNAs may play an important role in pathogenesis of $\mathrm{PE}$ and may become diagnostic markers for PE.

Clin Chem Lab Med 2009;47:923-9.
\end{abstract}

Keywords: gene ontology; microarray; microRNA; placenta; pre-eclampsia.

*Corresponding author: Yayi Hou, PhD, Immunology and Reproduction Biology Lab, Medical School, Nanjing University, Nanjing 210093, PR China

Phone: +86-25-83686441, Fax: +86-25-83686441, E-mail: yayihou@nju.edu.cn

Received March 4, 2009; accepted May 28, 2009

\section{Introduction}

Pre-eclampsia (PE) is a disease of pregnancy characterized by hypertension and proteinuria, developing after 20 weeks of gestation. It has been estimated that $5 \%-7 \%$ of pregnancies world wide are complicated by this disorder, resulting in a very large disease burden (1). Although its pathogenesis is incompletely understood, the placenta is considered to play a key role in the disease (2).

Recent studies on microRNA (miRNA) offer the possibility for developing a new class of molecular markers for diagnosis of PE. MiRNAs are short (19-25 nucleotides), single-stranded, and non-protein-coding RNAs (3) that regulate gene expression by binding to the $3^{\prime}$ untranslated region of the target mRNAs (4). They function in diverse biological processes, including development, differentiation, apoptosis, and oncogenesis (5). Moreover, recent research shows that many miRNAs are expressed abundantly in the human placenta (6).

Published data on miRNAs in human PE is surprisingly sparse. Pineles et al. (7) first reported the miRNA expression patterns in placentae with distinct pathologies including $\mathrm{PE}$ and $\mathrm{PE}+$ small-for-gestational age (SGA). However, they only identified the expression of 157 miRNAs using quantitative real-time reverse transcription-polymerase chain reaction (qRTPCR) for miRNA arrays. Roman et al. (8) reported the differential expression of miRNA in placenta of Hispanics with severe PE. Recently, there was another report published on miRNA in Chinese women with PE (9). This lack of data prompted us to determine and compare the expression profile of miRNA in placenta of Chinese patients with PE compared with normal placenta tissue. We wished to evaluate the potential clinical usefulness of miRNA as diagnostic markers.

\section{Materials and methods}

\section{Patients and tissue samples}

Placental tissue was obtained from women who were hospitalized in the Department of Gynecology and Obstetrics of The Affiliated Drum Tower Hospital of Nanjing University Medical School. Written consent was received from women prior to surgery. The hospital Ethics Committee approved the consent forms and the protocols for evaluation of the tissue. All placental tissues were obtained at the time of cesarean section. We selected 24 pregnancies complicated by severe late-onset PE with delivery occurring after 34 weeks. Also, 26 pregnant women with normal term pregnancy were recruited as the control group. The relevant clinical details for the patients are shown in Table 1. For the control group, women with chronic hypertension, cardiovascular disease, renal disease, hepatitis, diabetes, any evidence 
Table 1 Clinical characteristics of the study population.

\begin{tabular}{|c|c|c|c|}
\hline & $P E(n=24)$ & Control $(n=26)$ & p-Value \\
\hline Age, years & $28.1 \pm 1.3$ & $28.7 \pm 1.1$ & NS \\
\hline Gestational age at delivery, weeks & $37.0 \pm 0.2$ & $38.8 \pm 0.4$ & NS \\
\hline$\%$ of primiparae & $10(41.6 \%)$ & $15(57.6 \%)$ & NS \\
\hline Body mass index, $\mathrm{kg} / \mathrm{m}^{2}$ & $29.0 \pm 1.0$ & $27.2 \pm 1.2$ & NS \\
\hline Systolic blood pressure, $\mathrm{mm} \mathrm{Hg}$ & $161.5 \pm 4.1$ & $119.6 \pm 3.9$ & $<0.05$ \\
\hline Diastolic blood pressure, $\mathrm{mm} \mathrm{Hg}$ & $113.4 \pm 2.8$ & $81.7 \pm 3.3$ & $<0.05$ \\
\hline Proteinuria, mg/24 h & $2209.4 \pm 23.6$ & 0 & $<0.05$ \\
\hline Alanine aminotransferase, U/L & $33.9 \pm 8.6$ & $30.5 \pm 6.5$ & NS \\
\hline Blood urea nitrogen, $\mathrm{mmol} / \mathrm{L}$ & $4.1 \pm 0.3$ & $3.8 \pm 0.2$ & NS \\
\hline Platelet, $\times 10^{9} / \mathrm{L}$ & $157.9 \pm 22.1$ & $192.0 \pm 31.4$ & NS \\
\hline Birth weight, g & $2835.6 \pm 173.0$ & $3415.3 \pm 158.3$ & NS \\
\hline Placenta weight, g & $485.8 \pm 25.6$ & $526.3 \pm 28.4$ & NS \\
\hline
\end{tabular}

PE, pre-eclampsia; NS, non-significant.

of intrapartum infection or other complications of pregnancy complications, such as fetal anomalies or chromosomal abnormalities were excluded from this study.

$\mathrm{PE}$ was defined as gestational hypertension (systolic pressure $>140 \mathrm{~mm} \mathrm{Hg}$ or diastolic blood pressure $>90 \mathrm{~mm} \mathrm{Hg}$ on $\geq 2$ occasions after gestational week 20 ) with proteinuria ( $>0.3 \mathrm{~g} /$ day). Severe PE was defined by the presence of $\geq 1$ of the following: 1) severe gestational hypertension (systolic pressure $>160 \mathrm{~mm} \mathrm{Hg}$ or diastolic blood pressure $>110 \mathrm{~mm}$ $\mathrm{Hg}$ on $\geq 2$ occasions after gestational week 20); or 2) severe proteinuria ( $\geq 5 \mathrm{~g}$ protein in a 24 -h urine specimen) (ACOG practice bulletin) (10). We collected chorionic tissue blocks $\left(\sim 1 \mathrm{~cm}^{3}\right)$ from the central part of the placenta only. Contamination with mother decidua and amniotic membranes was excluded by morphological observation. Tissues were thoroughly washed with normal saline and then frozen in liquid nitrogen and stored at $-80^{\circ} \mathrm{C}$ until used.

\section{RNA extraction}

Total RNA included miRNA was extracted using Trizol Reagent (Invitrogen, Carlsbad, CA, USA) according to the manufacturer's instructions. RNA integrity was determined using formaldehyde denaturalization agarose gel electrophoresis. RNA concentrations were measured with the smartspec $^{\text {TM }}$ plus spectrophotometer (BIO-RAD, Hercules, CA, USA).

\section{MicroRNA microarray analysis}

Eight samples, four normal placentae (4 normal placentae were pooled to form a control group) and four placentae from women with severe PE (matched for gestational age at delivery and mother age) were assayed using a miRNA microarray chip (CapitalBio Corp, Beijing, China). We undertook miRNA expression analysis according to their instructions. We reported only those genes with significant $(p<0.05)$ differential expression of $\geq 2.0$-fold changes. $\mathrm{Mi}$ RNAs were further analyzed according to predicted targets found at miRBase (http://microrna.sanger.ac.uk/targets version 5).

\section{Mature microRNA quantitative real-time reverse transcription PCR (qRT-PCR)}

The method to quantify mature miRNA was performed as described previously (11). We used TaqMan ${ }^{\text {TM }}$ MicroRNA Assays (Applied Biosystems, Foster City, CA, USA). Total RNA was purified using mirVana miRNA isolation kit (Ambion, Austin, TX, USA) to enrich the small RNA fraction. Then, $10 \mathrm{ng}$ of total RNA was combined in the $15 \mu \mathrm{L}$ RT reaction: $1.5 \mu \mathrm{L} 10 \times \mathrm{RT}-\mathrm{PCR}$ buffer, $1 \mu \mathrm{L}$ of $50 \mathrm{U} / \mu \mathrm{L}$ MultiScribe RT enzyme, $0.15 \mu \mathrm{L} 100 \times$ dNTP mix $0.19 \mu \mathrm{L} 20 \mathrm{U} / \mu \mathrm{L}$ RNase-inhibitor, and $3 \mu \mathrm{L} 5 \times$ specific RT-primer and nuclease-free water to a total volume of $15 \mu \mathrm{L}$. The transcription reaction was incubated at $16^{\circ} \mathrm{C}$ for $30 \mathrm{~min}, 42^{\circ} \mathrm{C}$ for $30 \mathrm{~min}$, and $85^{\circ} \mathrm{C}$ for $5 \mathrm{~min}$. All reverse transcription reactions, including no-template controls and RT minus controls, were run in duplicate. Once the RT reactions are complete, the PCR reactions can be assembled. For a $20-\mu \mathrm{L}$ reaction, $10 \mu \mathrm{L}$ $2 \times$ Universal Master Mix, $1.32 \mu \mathrm{L}$ of the RT product, $1 \mu \mathrm{L}$ $20 \times$ TaqMan $^{\text {TM }}$ Assay, and $7.68 \mu \mathrm{L}$ nuclease-free water were combined. Subsequently, qRT-PCR was performed using an Applied BioSystems 7300 Sequence Detection System (Perkin-Elmer Applied Biosystems, Foster City, CA, USA). The reactions were incubated in a 96-well optical plate at $95^{\circ} \mathrm{C}$ for $10 \mathrm{~min}$, followed by 40 cycles at $95^{\circ} \mathrm{C}$ for $15 \mathrm{~s}$ and $60^{\circ} \mathrm{C}$ for $1 \mathrm{~min}$. All experiments were done in triplicate. The threshold cycle $(\mathrm{Ct})$ was determined using the default threshold settings. The $\mathrm{Ct}$ value was defined as the fractional cycle number at which fluorescence passes a fixed threshold. The relative amount of each miRNA to internal control was calculated using the equation $2^{-\Delta C_{t}}$, where $\Delta C_{t}=C_{\text {tmiRNA }}-C_{t U 6}$. All primers used are listed in Table 2 .

\section{Statistical analysis}

Results were expressed as mean \pm SEM. Statistical analysis was performed using unpaired Student's t-test, using GraphPad Prism 5 Demo software (GraphPad software, San Diego, CA, USA). A p $<0.05$ was considered to be statistically significant.

\section{Results}

\section{Characteristics of RNA samples}

The mean ratio of absorbance at 260 and $280 \mathrm{~nm}$ (A260/A280) of all 50 RNA samples amounted to $1.93 \pm 0.05$ (arithmetic mean $\pm S D$ ). RNA integrity was determined using formaldehyde denaturalization agarose gel electrophoresis (data not shown). The criterion for RNA quality is an A260/A280 ratio $>1.8$ and a clearly visible $28 \mathrm{~S}$ and $18 \mathrm{~S}$ rRNA band with a ratio of $1.0 \sim 2.0$ (28S:18S).

\section{MicroRNA microarray expression data}

We used the microarray platform CapitalBio Mammalian miRNA Array V3.0 consisting of 924 miRNA 


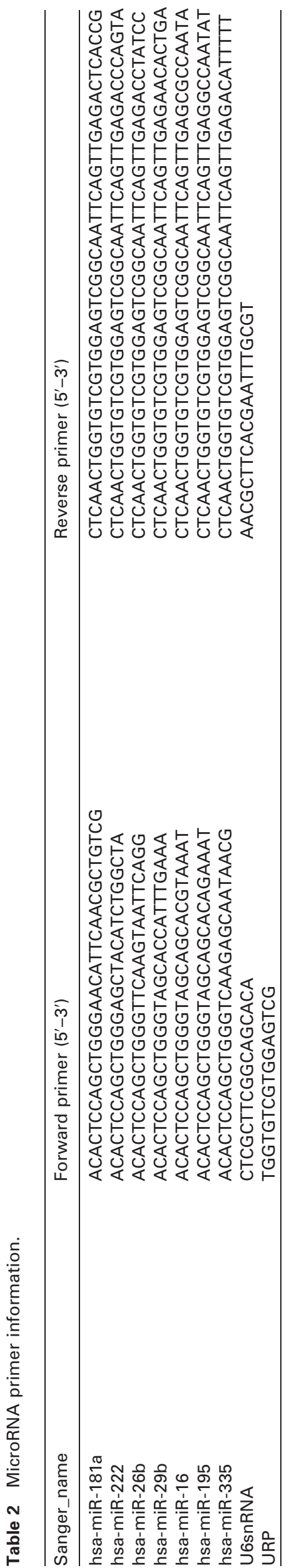

probes (677 human miRNAs) corresponding to the Sanger Center database miRBase version 10.0. First, we assessed the expression profile in normal placenta and placenta from women with severe PE. Several previous in depth comparative studies between microarray platforms and analysis procedures have indicated the very high reproducibility, sensitivity, and specificity of similar expression microarrays when using the recommended procedures $(12,13)$. Microarray data discussed in this publication have been deposited in the NCBI Gene Expression Omnibus (GEO, http://www.ncbi.nlm.nih.gov/geo/) and are accessible through GEO Series accession number GSE15789. These miRNAs were retained for further statistical analysis including SAM (14) and hierarchical cluster analysis (15) (Figure 1). After the raw data were normalized, we found 20 miRNAs to be up-regulated and seven miRNAs down-regulated in patients with severe PE compared with nomal placenta. The changes in miRNA identified in placentas from women with severe PE are shown in Table 3.

\section{Validation of microarray data by qRT-PCR analysis}

Further validation of aberrant miRNAs was determined using qRT-PCR in placentas from 24 women with severe PE and 26 placentas from women with normal pregnancy. We identified the seven most up-regulated miRNAs (miR-181a, miR-195, miR-222, miR-16, miR-29b, miR-26b and miR-335). As shown in Figure 2, the expressions of miR-16, miR-29b, miR195, miR-26b, miR-181a, miR-335 and miR-222 were significantly different in severe PE compared with normal placenta. These miRNAs were found to have the same expression trend as microarray analysis, but the discordance observed was not identical. This result was not surprising because qRT-PCR is a more sensitive technique compared with miRNA microarray.

\section{Target prediction and GO analysis}

Predicted targets of miRNAs differentially expressed in this study were determined using miRBase Targets (16) (Table 4). In addition, we used CapitalBio ${ }^{\circledR}$ Molecule Annotation System V4.0 to perform gene ontology (GO) analysis on the gene target lists of miR-16, miR-29b, miR-195, miR-26b, miR-181a, miR-335 and miR-222 and found that specific biological process categories were enriched (Table 5).

\section{Discussion}

In the present study, we profiled the expression of a number of miRNAs in placenta obtained from women with severe PE and from women with normal pregnancy. Of the 677 human miRNAs on the array of the expression values, 27 miRNAs were differentially expressed between placenta from women with severe $\mathrm{PE}$ and those with normal pregnancy (Table 3). There were 20 miRNAs that were up-regulated in PE compared with normal placenta, and seven miRNAs were 


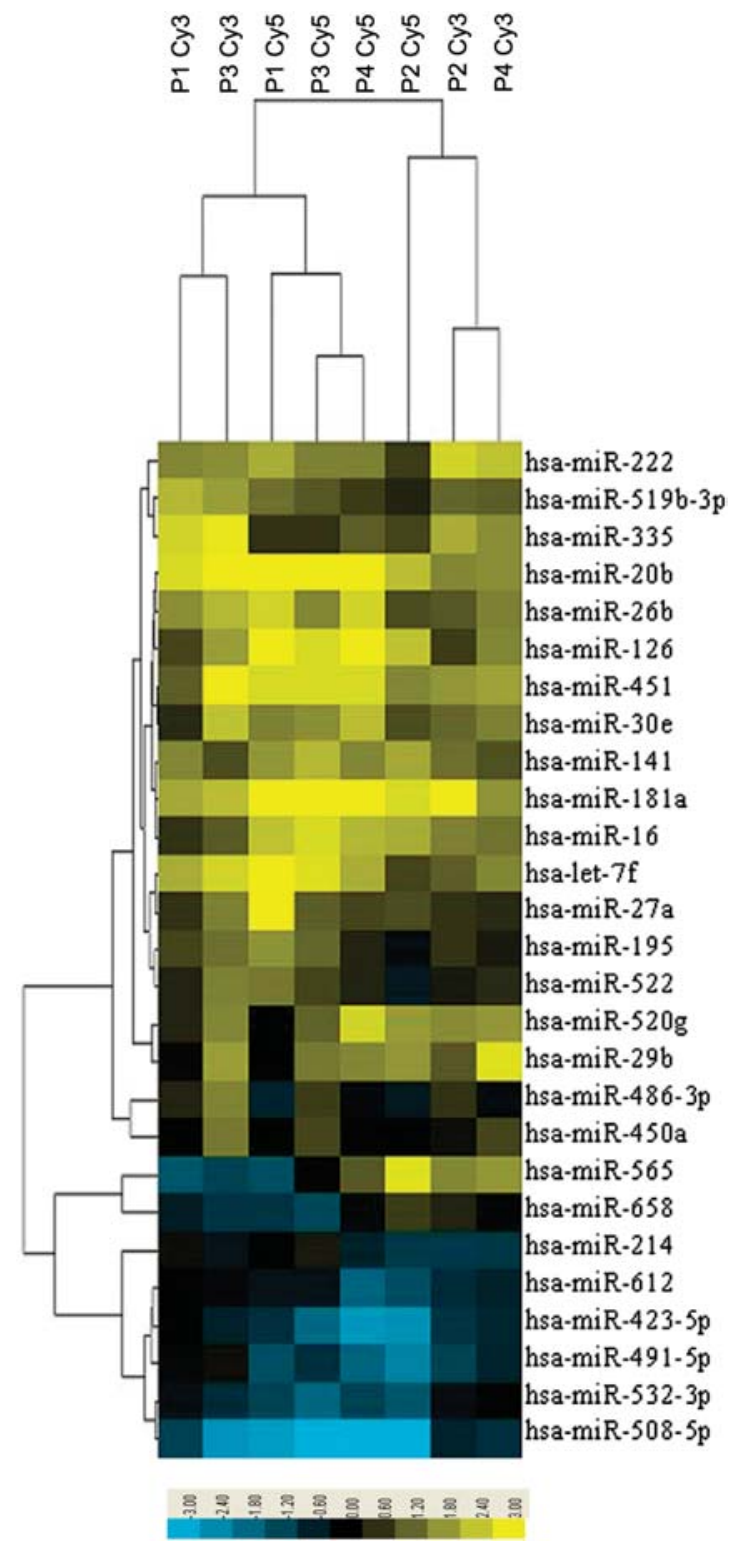

Figure 1 Hierarchical cluster analysis of differentially expressed miRNAs in placenta from women with severe preeclampsia (P1, P2, P3, P4) and normal placenta (composed of tissue from four normal placentas).

Each row represents a microRNA and each column represents a sample pair of placenta from women with severe preeclampsia and normal pregnancy. The color indicates high expression (yellow) or low expression (blue) according to the color legend shown below. The microRNA data were clustered according to their similarities in expression pattern in microRNAs and tissues. The dendrograms display similarity of expression among these cohorts.

down-regulated. Several studies have reported the differential expression of miRNA in normal placenta and PE placenta. Pineles et al. (7) found that expression of two miRNAs (miR-210 and miR-182) was significantly higher in PE than in the control group. Roman et al. (8) found that there were 91 dysregulated miRNAs (38 miRNAs were down-regulated and 53 were up-regulated). Zhu et al. (9) found that 11 miRNAs were overexpressed and 23 miRNAs were underexpressed in PE. When compared with their results, there was no overlap with our data. This
Table 3 The list of miRNAs that were differentially expressed between pre-eclampsia compared with normal placenta.

\begin{tabular}{lc}
\hline Name & Fold change \\
\hline hsa-miR-181a & 6.58 \\
hsa-miR-195 & 4.23 \\
hsa-miR-222 & 4.08 \\
hsa-miR-16 & 3.65 \\
hsa-miR-29b & 3.57 \\
hsa-miR-26b & 3.24 \\
hsa-miR-335 & 2.91 \\
hsa-miR-126 & 2.76 \\
hsa-miR-7f & 2.68 \\
hsa-miR-565 & 2.61 \\
hsa-miR-20b & 2.57 \\
hsa-miR-27a & 2.46 \\
hsa-miR-141 & 2.42 \\
hsa-miR-519b-3p & 2.37 \\
hsa-miR-451 & 2.34 \\
hsa-miR-450a & 2.25 \\
hsa-miR-520g & 2.20 \\
hsa-miR-30e & 2.16 \\
hsa-miR-522 & 2.12 \\
hsa-miR-486-3p & 2.05 \\
hsa-miR-214 & -2.04 \\
hsa-miR-658 & -2.13 \\
hsa-miR-532-3p & -2.38 \\
hsa-miR-423-5p & -3.13 \\
hsa-miR-491-5p & -3.70 \\
hsa-miR-612 & -4.35 \\
hsa-miR-508-5p & -7.69 \\
\hline & \\
\hline &
\end{tabular}

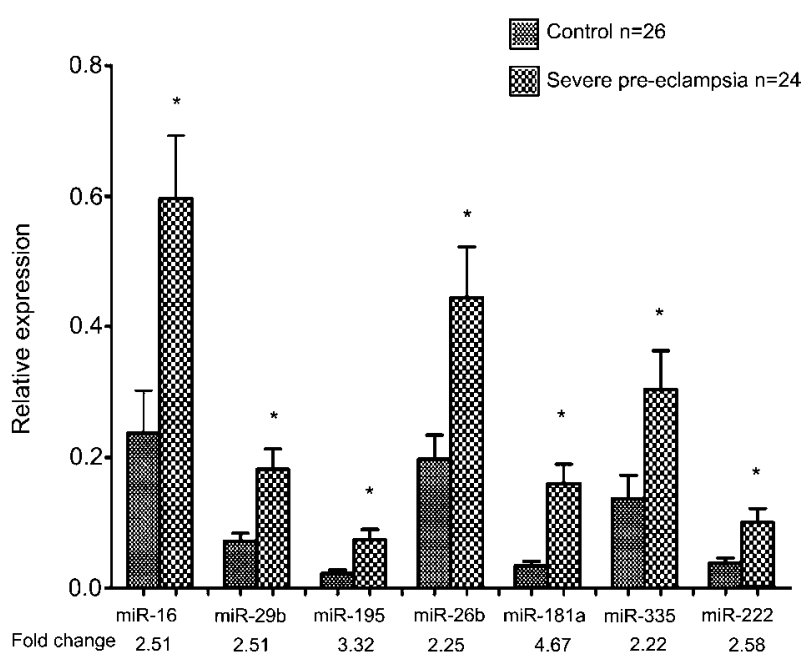

Figure 2 Real time PCR expression of miR-16, miR-29b, miR-195, miR-26b, miR-181a, miR-335 and miR-222 in normal placenta and placenta from women with severe preeclampsia.

Bar graphs show real time PCR expression of miR-16, miR29b, miR-195, miR-26b, miR-181a, miR-335 and miR-222 in placenta from women with normal pregnancy and placenta from women with severe pre-eclampsia. The data are presented as relative expression following normalization. Data represent mean \pm SE. ${ }^{*}$ Significantly different forms. $p<0.05$ was considered significant.

might be attributed to the different array platforms and ethic groups and gestation age of the placenta.

It is estimated that $\sim 30 \%$ of genes are potential targets of miRNA function $(17,18)$. Since each miRNA is 
Table 4 MiRNAs and gene targets.

\begin{tabular}{|c|c|c|}
\hline miRNA & $\begin{array}{l}\text { Chromosomal } \\
\text { location }\end{array}$ & Predicted target genes \\
\hline hsa-miR335 & $7 q 21.1$ & $\begin{array}{l}\text { PLGF,PGR,ACVR1C,IGR2BP2,HIF1AN,COL4A2,IL-17RD,KIAA } \\
\text { 0256,MAP3K2,EBF4,TP53NP2,ECFN2,HOXB3,VAV2,MEF2D }\end{array}$ \\
\hline hsa-miR181a & $9 q 33.3 / 1 q 31.3$ & $\begin{array}{l}\text { TGFBRAP1,IL18R1,IL1R1,FGFR2,KIR2DL1,IL12RB1,KIAA1632, } \\
\text { TNFAIP6,HLA-C,HLA-B,HLA-DRA,TLR1, IL2,SAP30,TGFBI, } \\
\text { CD164L2,CD1E,KLRD1,IFNG,CCL7,CCL11,CCL8, MMP7 }\end{array}$ \\
\hline hsa-miR222 & xp11.3 & $\begin{array}{l}\text { IL18RAP,ADAM17,ADAM8,KIAA1279,AGTPBP1,KIR3DL1, } \\
\text { ICAM4,HLA-F,PI16,ADAMTS16, CD180,IL17RB,ADAM22, } \\
\text { IFRD1,CD99,CYR61,CD68,MMP1,IL18 }\end{array}$ \\
\hline has-miR16 & $3 q 26.1 / 13 q 14.3$ & $\begin{array}{l}\text { C2orf34,hcG_1790474,IL18RAP,CD40,FGFR2,FGF8,KIAA1462, } \\
\text { FLT3,ADAMTS18,GFER,TLE4,ADAMTSL1,CD274,CD37,CD97, } \\
\text { PIGB,EGFL8,TKR1,NKKB1,CXCL3,PPAP2A,CD99,TGFBR3, } \\
\text { CD48,ADAMTS4,IL20,VWF,CD163,CCL13,CCL4,CCL4L, } \\
\text { FGFR1,IL10RB,CD151,MMP3 }\end{array}$ \\
\hline hsa-miR26b & $2 q 35$ & $\begin{array}{l}\text { IL18R1,MMP21,PPA1,KIAA1279,ANGPTL2,ADAMTSL1,PEG3, } \\
\text { KIR3DL1,KIR2DL4,KIR2DL1,FGF21,CDC34,MAP3K2,STAT4, } \\
\text { PRL,EGF,IRF2,CCL26,CSFIRA,IL13RA1,KIAA2013,ETV3,CD1C, } \\
\text { CD1E,IL20,IFNG,CD68,CCL13,SERPINA10,MMP12 }\end{array}$ \\
\hline hsa-miR29b & $1 q 32.2 / 7 q 32.3$ & $\begin{array}{l}\text { ILIF9,PIGF,CD40,ADAMTS18,IL32,HIF3A,ADAMTS10,ANGPTL4, } \\
\text { TNFRSF9,KIAA0101,ADAMTS7,HLA-DQA2,VEGFA,IL20RA, } \\
\text { ADAMTS6,SRP19,CDC7,IL4,CD55,IFNG,IL-22,TGFB3,LPL, } \\
\text { CD248,MMP8 }\end{array}$ \\
\hline hsa-miR195 & $17 p 13.1$ & $\begin{array}{l}\text { CD40,ADAM12,FGF8,KIAA1462,ADAMTS1,CD37,MICA,LTB, } \\
\text { EGFL8,VEGFA,TLR1,IL15,CXCL3,PPAP2A,ILF2,CD48,IL20, } \\
\text { CD163,CCL4,CCL4L1,IL10RB,MMP3HLA-DRB1 }\end{array}$ \\
\hline
\end{tabular}

Note: see citations in the text and http://microrna.sanger.ac.uk/sequences/regarding most updated predicted target genes.

Table 5 The results of gene ontology analysis of targets of differentially expressed miRNAs.

\begin{tabular}{|c|c|c|c|c|c|c|c|}
\hline Biological process category, $\mathrm{n}$ & $\begin{array}{l}\text { Targets of } \\
\text { miR-16 }\end{array}$ & $\begin{array}{l}\text { Targets of } \\
\text { miR-26b }\end{array}$ & $\begin{array}{l}\text { Targets of } \\
\text { miR-29b }\end{array}$ & $\begin{array}{l}\text { Targets of } \\
\text { miR-195 }\end{array}$ & $\begin{array}{l}\text { Targets of } \\
\text { miR-335 }\end{array}$ & $\begin{array}{l}\text { Targets of } \\
\text { miR-181a }\end{array}$ & $\begin{array}{l}\text { Targets of } \\
\text { miR-222 }\end{array}$ \\
\hline Cell death & 16 & 8 & 9 & 12 & 10 & 7 & 7 \\
\hline Immune system process & 12 & 9 & 9 & 20 & 9 & 17 & 12 \\
\hline Immune response & 7 & 5 & 5 & 8 & 7 & 5 & 7 \\
\hline $\begin{array}{l}\text { Regulation of cellular physiological } \\
\text { process }\end{array}$ & 44 & 38 & 33 & 44 & 45 & 29 & 29 \\
\hline Signal transduction & 41 & 28 & 29 & 34 & 36 & 35 & 30 \\
\hline Organ development & 10 & 12 & 14 & 14 & 16 & 13 & 12 \\
\hline System development & 7 & 8 & 5 & 9 & 9 & 6 & 5 \\
\hline Regulation of signal transduction & 6 & 6 & 5 & 6 & 4 & 7 & 5 \\
\hline Tissue development & 5 & 1 & 3 & 6 & 5 & 3 & 3 \\
\hline Cell proliferation & 4 & 3 & 3 & 5 & 6 & 4 & 4 \\
\hline Cell development & 2 & 6 & 4 & 4 & 5 & 2 & 3 \\
\hline
\end{tabular}

Values expressed as number of genes targeted by miRNA.

predicted to have a broad range of targets, even an alteration in the expression of a single miRNA could have a significant impact on the outcome of diverse biological functions associated with these genes. As such, the absence or altered expression of these and other miRNAs could result in expression re-programming of many of their target genes in PE. The increased miRNA expression in PE suggests the down-regulation of potential target genes which may contribute to the pathology of PE. Among the genes predicted as the target of miR-16, miR-26b, miR-29b, miR-335, miR-222, miR-181a and miR-195 (Table 4), we found the target genes of these miRNAs were related to angiogenic factors, such as vascular endothelial growth factor A (VEGF-A) and placental growth factor (PLGF) (19) which are important for the development of PE (see below). Furthermore, we performed GO analysis on the target genes, and found that a consid- erable number of genes have been identified related to immune response, signal transduction and angiogenesis. These are all thought to be involved in the maintenance of pregnancy and the development of PE (Table 5).

Perturbation of angiogenesis has been proposed as one of the key features of PE. It is speculated that there is an imbalance in the production of angiogenic growth factors at the maternal-fetal interface. Recent lines of evidence suggest that failed trophoblast invasion is linked to the maternal vascular pathology through abnormal placental production of vasculogenic and angiogenic factors, such as $\operatorname{VEGF}(20,21)$. Some angiogenic growth factors, such as angiopoietin 2 (Ang2), PLGF, and VEGF-C, fibroblast growth factor (FGF), interferon- $\gamma$ (IFN- $\gamma$ ), and transforming growth factor- $\beta$ (TGF- $\beta$ ), are involved in pregnancy (22). These molecules may be useful markers for pre- 
dicting PE $(23,24)$. Zhou et al. (25) demonstrated that the expressions of VEGF-A and VEGF receptor-1 are down-regulated in cytotrophoblasts of pre-eclamptic placenta. Several investigations have demonstrated that other growth factors and their receptors, such as PLGF and insulin-like growth factor I (IGF-I) are also dysregulated in serum or placental tissue of women with PE $(26,27)$. Mo et al. (28) found that cysteine-rich 61 (CYR61) is essential for placental development and vascular integrity. Gellhaus et al. (29) found that CYR61 is significantly decreased in pre-eclamptic placenta. Interestingly, our research revealed that these angiogenic growth factors were potential targets of the altered miRNA, such as CYR61, PLGF, VEGF-A which were targets of miR-222, miR-335 and miR-195, respectively. Moreover, it is reported that miRNA is strongly implicated in angiogenesis (30).

The association between PE and altered miRNA expression suggests the possibility of a functional role for miRNA in this disease. Our finding may provide novel targets for further investigation of the pathogenesis of PE and these differential miRNAs may be potential markers for the diagnosis of PE. Moreover, Chim et al. found that placental miRNAs represent a novel class of fetal nucleic acid markers in maternal plasma (31). Therefore, it will be interesting to determine whether the differential expression profiles of miRNAs found in placenta correlates with those from maternal plasma, especially since these may serve as diagnostic markers of PE.

\section{Conflict of interest disclosures}

None declared.

\section{Acknowledgements}

This work was supported by the Project Foundation of Jiangsu Province Department of Health, China (Grant No. H200754) and Special Research Grant (XK200709 to YH) for the Key Laboratory from the Department of Health, Jiangsu Province.

\section{References}

1. Sibai B, Dekker G, Kupferminc M. Pre-eclampsia. Lancet 2005;365:785-99.

2. Myatt L. Role of placenta in preeclampsia. Endocrine 2002;9:103-11.

3. Lee RC, Ambros V. An extensive class of small RNAs in Caenorhabditis elegans. Science 2001;294:862-4.

4. Lai EC. MicroRNAs are complementary to 3'UTR sequence motifs that mediate negative post-transcriptional regulation. Nat Genet 2002;30:363-4.

5. Bushati N, Cohen SM. MicroRNA functions. Annu Rev Cell Dev Biol 2007;23:175-205.

6. Lim LP, Lau NC, Garrett-Engele P, Grimson A, Schelter JM, Castle J, et al. Microarray analysis shows that some microRNAs downregulate large numbers of target mRNAs. Nature 2005;433:769-73.

7. Pineles BL, Romero R, Montenegro D, Tarca AL, Han YM, Kim YM, et al. Distinct subsets of microRNAs are expressed differentially in the human placentas of patients with pre-eclampsia. Am J Obstet Gynecol 2007; 196:261.e1-6.

8. Roman A, Ahn HW, Qi Zhu, Zhou XC, Gao XL, Rajkovic $A$, et al. MicroRNA expression in placenta of patients with pre-eclampsia. Am J Obstet Gynecol 2008;199:S78.

9. Zhu X-M, Han T, Sargent IL, Yin G-W, Yao Y-Q. Differential expression profile of microRNAs in human placentas from preeclamptic pregnancies vs. normal pregnancies. Am J Obstet Gynecol 2009;200:1e1-7.

10. ACOG practice bulletin. Diagnosis and management of pre-eclampsia and eclampsia. Int J Gynaecol Obstet 2002;77:67-75.

11. Chen CF, Ridzon DA, Broomer AJ, Zhou ZH, Lee DH, Nguyen JT, et al. Real-time quantification of microRNAs by stem-loop RT-PCR. Nucleic Acids Res 2005;33:e179.

12. Shi L, Reid LH, Jones WD. The MicroArray Quality Control (MAQC) project shows inter- and intraplatform reproducibility of gene expression measurements. Nat Biotechnol 2006;24:1151-61.

13. Guo Y, Guo HY, Zhang L, Xie H, Zhao X, Wang F. Genomic analysis of anti-hepatitis B virus (HBV) activity by small interfering RNA and lamivudine in stable HBVproducing cells. J Virol 2005;79:14392-403.

14. Tusher VG, Tibshirani R, Chu G. Significance analysis of microarrays applied to the ionizing radiation response. Proc Natl Acad Sci USA 2001;98:5116-21.

15. Eisen MB, Spellman PT, Brown PO, Botstein D. Cluster analysis and display of genome-wide expression patterns. Proc Natl Acad Sci USA 1998;95:14863-8.

16. Griffiths-Jones S, Grocock RJ, Van Dongen S, Bateman A, Enright AJ. miRBase: microRNA sequences, targets and gene nomenclature. Nucleic Acids Res 2006;34: D140-4.

17. Ambros V. The functions of animal microRNAs. Nature 2004;431:350-5.

18. Yu J, Wang F, Yang GH, Wang FL, Ma YN, Du ZW, et al. Human microRNA clusters: genomic organization and expression profile in leukemia cell lines. Biochem Biophys Res Commun 2006;349:59-68.

19. Carty DM, Delles C, Dominciczak AF. Novel biomarkers for predicting pre-eclampsia. Trends Cardiovas Med 2008;18:186-94.

20. Fisher SJ. The placental problem: linking abnormal cytotrophoblast differentiation to the maternal symptoms of preeclampsia. Reprod Biol Endocrinol 2004;2:53.

21. Mayhew TM, Charnock-Jones DS, Kaufmann P. Aspects of human fetoplacental vasculogenesis and angiogenesis III changes in complicated pregnancies. Placenta 2004;25:127-39.

22. Lash GE, Schiessl B, Kirkley M, Innes BA, Cooper A, Searle RF, et al. Expression of angiogenic growth factors by uterine natural killer cells during early pregnancy. $J$ Leukoc Biol 2006;80:572-80.

23. Vivo AD, Giovanni Baviera G, Giordano D, Todarello G, Corrado F, D'anna R. Endoglin, PIGF and sFlt-1 as markers for predicting pre-eclampsia. Acta Obstet Gyn Scan 2008;87:837-42.

24. Lim JH, Kim SY, Park SY, Yang JH, Kim MY, Ryu HM. Effective prediction of preeclampsia by a combined ratio of angiogenesis-related factors. Obstet Gynecol 2008; 111:1403-9.

25. Zhou Y, McMaster M, Woo K, Janatpour M, Perry J, Karpanen $T$, et al. Vascular endothelial growth factor ligands and receptors that regulate human cytotrophoblast survival are dysregulated in severe preeclampsia and hemolysis, elevated liver enzymes, and low platelets syndrome. Am J Pathol 2002;160:1405-23.

26. Lam C, Lim KH, Karumanchi SA. Circulating angiogenic factors in the pathogenesis and prediction of preeclampsia. Hypertension 2005;46:1077-85.

27. Sane DC, Anton L, Brosnihan KB. Angiogenic growth factors and hypertension. Angiogenesis 2004;7:193-201. 
28. Mo FE, Muntean AG, Chen CC, Stolz DB, Watkins SC, Lau LF. CYR61 (CCN1) is essential for placental development and vascular integrity. Mol Cell Biol 2002;22:8709-20.

29. Gellhaus A, Schmidt M, Dunk C, Lye SJ, Kimmig R, Winterhager $\mathrm{E}$. The circulating proangiogenic factors CYR61 (CCN1) and NOV (CCN3) are significantly decreased in placentae and sera of preeclamptic patients. Mol Hum Reprod 2006;12:389-99.
30. Suárez Y, Fernández-Hernando C, Yu J, Gerber SA, Harrison KD, Pober JS, et al. Dicer-dependent endothelial microRNAs are necessary for postnatal angiogenesis. Proc Natl Acad Sci USA 2008;105:14082-7.

31. Chim SS, Shing TK, Hung EC, Leung TY, Lau TK, Chiu RW, et al. Detection and characterization of placental microRNAs in maternal plasma. Clin Chem 2008;54: 482-90. 